\title{
Construction and validation of instrument to assess the quality of infection control programs
}

\author{
Construção e validação de instrumento para avaliação da \\ qualidade dos programas de controle de infecção \\ Construcción y validación del instrumento para evaluar la \\ calidad de los programas de control de infecciones
}

\author{
André Luiz Silva Alvima \\ Andrea Gazzinellia \\ Bráulio Roberto Gonçalves Marinho Couto ${ }^{b}$
}

\section{How to cite this article:} Alvim ALS, Gazzinelli A, Couto BRGM. Construction and validation of instrument to assess the quality of infection control programs. Rev Gaúcha Enferm. 2021;42:e20200135. doi: https://doi. org/10.1590/1983-1447.2021.20200135
Universidade Federal de Minas Gerais (UFMG) Programa de Pós-Graduaçăo em Enfermagem. Belo Horizonte, Minas Gerais, Brasil.

b Centro Universitário de Belo Horizonte (UniBH), Departamento de Engenharia e Estatística. Belo Horizonte, Minas Gerais, Brasil.

\section{ABSTRACT}

Objective: To build and validate an instrument to assess hospital infection control programs.

Method: Methodological study that was developed in seven stages. The instrument items were categorized into the structure, process and result components. 10 expert judges participated, who evaluated the psychometric properties and validated the content using the Likert scale. The pre-test was carried out with 98 health professionals, from April to July 2018. For reliability analysis, Cronbach's alpha test was used.

Results: Regarding the content validity index, the score made by expert judges ranged from 0.777 to 1.00 , with mean of 0.902 ( \pm 0.076). The Cronbach's alpha test showed good internal consistency of the items (0.82).

Conclusion: An instrument to assess hospital infection control programs was developed and validated, which showed good reliability and can be efficiently used at national level.

Keywords: Validation study. Cross infection. Health services research. Infection control.

\section{RESUMO}

Objetivo: Construir e validar um instrumento de avaliação dos programas de controle de infecção hospitalar.

Método: Estudo metodológico que foi desenvolvido em sete etapas. Os itens do instrumento foram categorizados nos componentes de estrutura, processo e resultado. Participaram 10 juízes especialistas que avaliaram as propriedades psicométricas e validaram 0 conteúdo através da escala de Likert. 0 pré-teste foi realizado com 98 profissionais de saúde, no período de abril a julho de 2018. Para análise de confiabilidade utilizou-se o teste alfa de Cronbach.

Resultados: Em relação ao índice de validade de conteúdo, a pontuação feita pelos juízes especialistas variou de 0,777 a 1,00, com média de 0,902 ( $\pm 0,076)$. 0 teste alfa de Cronbach evidenciou boa consistência interna dos itens $(0,82)$.

Conclusão: Foi elaborado e validado instrumento de avaliação dos programas de controle de infecção hospitalar, que apresentou boa confiabilidade, podendo ser utilizado de forma eficiente em nível nacional.

Palavras-chave: Estudos de validação. Infecção hospitalar. Pesquisa sobre serviços de saúde. Controle de infecções.

\section{RESUMEN}

Objetivo: Construir y validar un instrumento para evaluar los programas de control de infecciones hospitalarias.

Método: Estudio metodológico desarrollado en siete etapas. Los ítems del instrumento se clasificaron en componentes de estructura, proceso y resultado. Participaron 10 jueces expertos, quienes evaluaron las propiedades psicométricas y validaron el contenido utilizando la escala Likert. La prueba previa se llevó a cabo con 98 profesionales de la salud, de enero a marzo de 2018. Para el análisis de confiabilidad, se utilizó la prueba alfa de Cronbach.

Resultados: En cuanto al índice de validez de contenido, la calificación realizada por jueces expertos varió de 0.777 a 1.00, con un promedio de 0.902 ( \pm 0.076). La prueba alfa de Cronbach mostró una buena consistencia interna de los ítems $(0,82)$.

Conclusión: Se desarrolló y validó un instrumento para evaluar los programas de control de infecciones hospitalarias, que mostró una buena fiabilidad y se puede utilizar de manera eficiente a nivel nacional.

Palabras clave: Estudio de validación. Infección hospitalaria. Investigación sobre servicios de salud. Control de infecciones. 


\section{口INTRODUCTION}

Healthcare-Related Infections (HAls) have been considered a problem for several centuries with a significant impact on morbidity and mortality and healthcare costs. These are adverse events that affect public health worldwide and can be avoided when healthcare services effectively implement an infection control program ${ }^{(1-2)}$.

The ordinance 2,616 of 12 May 1998 defines the Hospital Infection Control Program (HICP) as a set of actions developed deliberately and systematically, with a view to reducing the maximum possible incidence and severity of infections ${ }^{(3)}$. It is recommended a multifaceted approach by health professionals for accomplishing with the HICP, tracing improvements in the structure, process and result components. This triad, referred to in this study as the quality components, should promote a consolidated relationship in the fight against HAls both at the local and national level ${ }^{(4-5)}$.

The literature presents central HICP quality requirements through recommendations to combat major health threats, such as antimicrobial resistance, pandemics and emerging diseases ${ }^{(1-2,6)}$. However, Brazil still has diversified actions developed by the HICP and research on the theme focuses on structural and process assessment as a requirement for prevention and control of $\mathrm{HAls}^{(7-8)}$.

The health professionals that compose the Hospital Infection Control Committee (HICC) and the Hospital Infection Control Service (HICS) must guarantee the operationalization of the actions outlined in the Program, analyzing it periodically to check compliance. In this case, it is indicated the use of an instrument that provides subsidies for data compilation and measurement of results ${ }^{(6-7)}$.

National researches that analyzed the quality of the HICP found gaps between practice and recommendations ${ }^{(7-10)}$. All of them used, as a reference, the same assessment instrument published in the literature in $2011^{(11)}$. The tool has strong potential for diagnosing service quality. However, HAls prevention and control recommendations have been updated, including bundles, multimodal strategies, governmental epidemiological surveillance systems and patient safety policies, elucidating the construction of a new instrument that helps and encourages continuous improvement ${ }^{(2)}$.

The present study is justified by the importance of building a reliable and reproducible instrument, in any infection control service, which is able to validate the various contents through scientific evidences. It is highlighted the relevance of providing subsidies for the elaboration of new guidelines aimed at reducing infectious diseases.

In this context, the guiding question of the study was thus outlined: can the psychometric properties of the instrument to assess infection control programs become valid and reliable for measuring what is proposed in relation to quality components? Thus, the objective of this study is to build and validate an instrument to assess hospital infection control programs.

\section{METHOD}

It is a methodological study developed in seven stages: establishment of the conceptual framework; definition of the instrument's objectives and the population involved; construction of items and response scales; selection and organization of items; structuring of the instrument; content validity and pre-test (Figure 1) $)^{(12)}$.

Stages 1 and 2 were consisted by a narrative review of the literature to deepen knowledge about the topic. The search for articles included the databases of Latin American and Caribbean Literature in Health Sciences (Literatura Latino-Americana e do Caribe em Ciências da Saúde - LILACS), Scopus and Web of Science. The scientific recovery strategy included the MeSH descriptors: "Infection Control" AND "Hospital Infection Control Program" AND"Quality of Health Care". Articles published between January 2008 and February 2018, in Portuguese, English and Spanish, were analyzed. Subsequently, the assessment instrument was built by the researchers based on the data collected, in addition to the Resolutions of the Collegiate Directorate (RCDs) in force, current national ordinances and international guidelines.

Nine published articles were selected, mainly in Scopus (55.6\%) and Web of Science (33.3\%). Only 1 (11.1\%) study captured at LILACS met the inclusion criteria. The review process included the results on the organizational infrastructure, the activities developed in the health services and the quality indicators in infection control.

The elaboration of items and response scales constituted the third methodological stage of this study. The instrument was composed by 36 questions, categorized in the components of structure, process and result. The Donabedian triad was chosen because it represents a careful approach to assess the safety and quality of a specific service ${ }^{(5)}$. The instructions on how to proceed with the assessment to validate the tool were also associated.

Stages four and five contemplated the structuring of the tool named "Instrument to assess Hospital Infection Control Programs". All questions were followed by the questions: "Is it necessary to eliminate this question? (yes/no/partially)" and "Is it necessary to adjust the instrument for this question (yes/no/partially)?". In addition, an open space was included for expert judges to carry out the trial and other observations, when necessary. The initial model was built using Microsoft Excel (version 15.0) and then migrated to the Google Docs platform. 


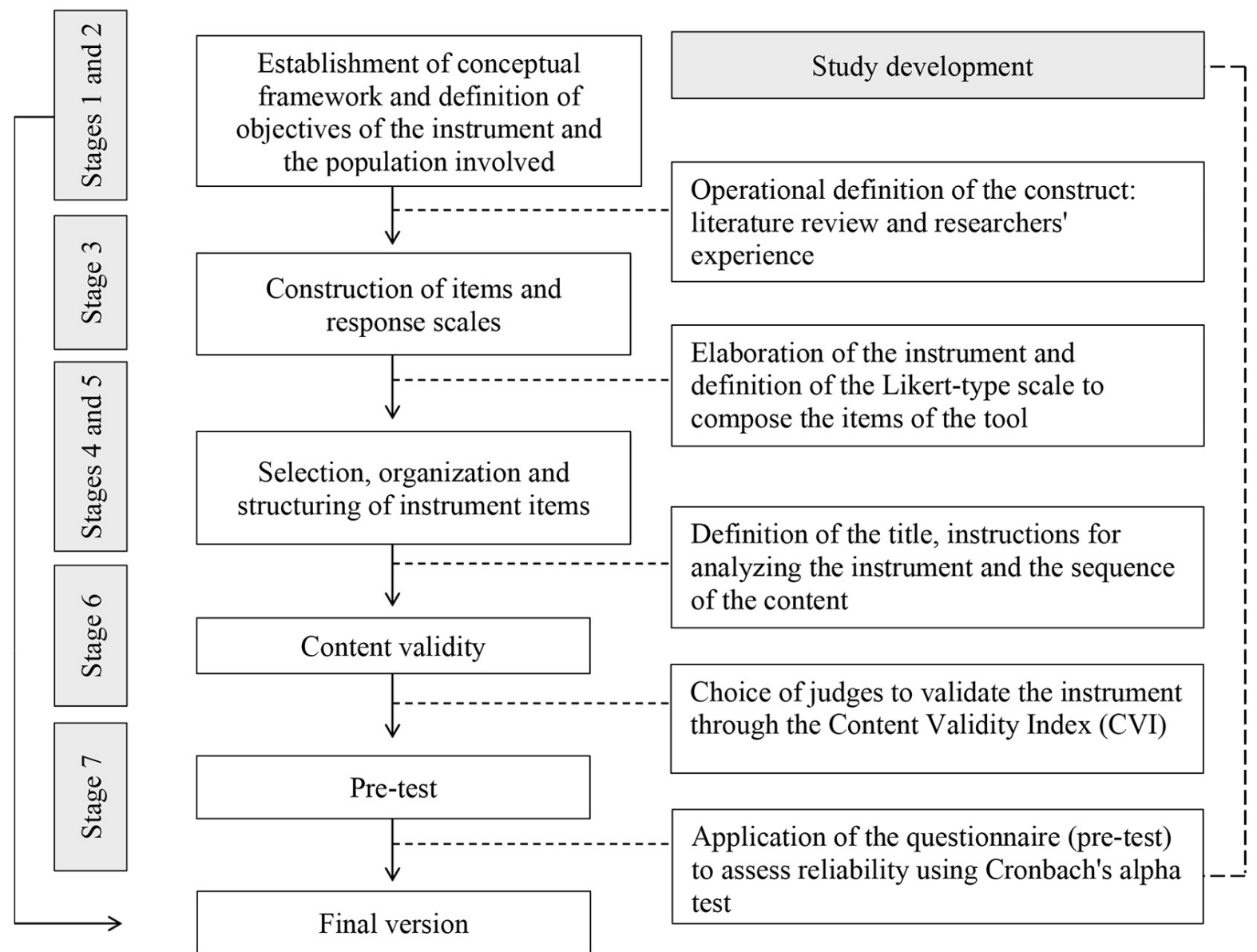

Figure 1 - Methodological stages for the construction and validation of the instrument Source: (12)

Stage 6 was represented by the choice of judges for content validity. In this phase, it was opted for the use of the Delphi technique, which is considered a tool that seeks a consensus of opinions among specialists regarding a particular research object ${ }^{(13)}$. The researchers in this study established two rounds to identify the agreement of most participants. Information to consensus was recorded on the Google Forms platform.

In the period from February to March 2018, the experts had their respective curricula evaluated on the Lattes Platform (http://lattes.cnpq.br/) of the National Council for Scientific and Technological Development (Conselho Nacional de Desenvolvimento Científico e Tecnológico - (NPq), by the subject criterion (infection related to health care) and filters (academic formation/degree, professional activity and institution). The selection of experts met the following eligibility criteria: having 10 years or more of experience in the HICS area, being active in public or private service. At the end, the sample consisted of 10 post-graduate professionals in epidemiology and infection control, who accepted to participate after sending an invitation letter, via email.

To verify the measured construct and evaluate the psychometric properties, the Content Validity Index (CVI) was adopted. Each of the 36 questions was accompanied by the Likert scale, with scores ranging from 1 to 4 , in which: 1 = non-equivalent item; 2 = item needs major revision; 3 = equivalent item, and 4 absolutely equivalent item. To calculate the $\mathrm{CVI}$, the following formula was used: number of responses 3 or $4 /$ total number of responses. Finally, the acceptable agreement index was standardized, being at least 0.80 and, preferably, greater than $0.90^{(14)}$.

Stage 7 consisted of applying the pre-test and assessment of the instrument's internal consistency. Data collection took place from April to July 2018. Initially, 142 professionals were invited who were part of a multiplatform application of HICC specialists from the Universidade Federal de São Paulo (UNIFESP). All worked in health services located in the five official regions of Brazil. The inclusion criteria were complied, 
according to the requirements established in stage 6 . However, 44 professionals (30.9\%) were excluded because they refused to participate in the study. The final sample, therefore, consisted by 98 participants selected using the non-probabilistic sampling technique for convenience.

The instrument for assessing responsiveness was sent through a link that allowed the release of complete and reliable data from the participants, maintained privacy, and updated information in real time. For reliability analysis it was used Cronbach's alpha test through the Statistical Package for the Social Sciences (SPSS)' software, establishing values above 0.70 as satisfactory ${ }^{(14)}$.

The study follows the ethical principles contained in Resolution 466/2012 of the National Health Council. The content of the instrument could only be accessed after reading and consenting of participants through the Informed Consent Form (ICF). As a way of preserving anonymity, the researchers avoided questions related to name, address and telephone number. The project was approved by the Research Ethics Committee under number of statement:2,340,091 and CAAE 78299817.0.0000.5126 on 10/20/2017.

\section{RESULTS}

Most of the expert judges were male (60\%), residing in the southeast region (50\%) and had a specialization in epidemiology and hospital infection control (70\%) with the highest academic degree. The age of the participants ranged from 35 to 60 years, with an average of 42.8 ( \pm 8.7). It is noteworthy that all the evaluators worked in hospitals $(100 \%)$, of which half were medium-sized (50\%). Most professionals were nurses (80\%). There was the participation of two infectologists who also had a specialization in HICC.

From the total of ten expert judges, four requested the synthesis of questions no.1, no. 2 and no.21, justifying that the breadth of the sentence did not add pertinent information to the evaluation process. Two suggested changes in the format of questions no. 10 and no. 31 and only one participant requested the reshaping of questions no.14, no. 29 and no. 33. All suggestions were related to improving the agreement and semantics of the Portuguese language and also, of the specifics terminologies to the area.

Regarding the $\mathrm{CVI}$, the score made by the expert judges ranged from 0.777 to 1.00 , with a mean of 0.902 ( $\mathrm{s} d \pm 0.076$ ) (Figure 2). It was observed that the 36 questions from the first Delphi round, obtained satisfactory results in relation to the instrument's content validation.

The second round reaffirmed the CVI values among the items of the instrument $(0.908 \pm 0.064)$, presenting itself above the recommended. In this case, it was not necessary to perform the third round of Delphi (Table 1).

It is noteworthy that the results of the instrument's internal consistency, evaluated by question, obtained satisfactory values, and remained above what is recommended by the studies. The items presented Cronbach's alpha test of 0.82 $( \pm 5.2)$ with a mean of 24.15 and variance of 24 (Table 2).

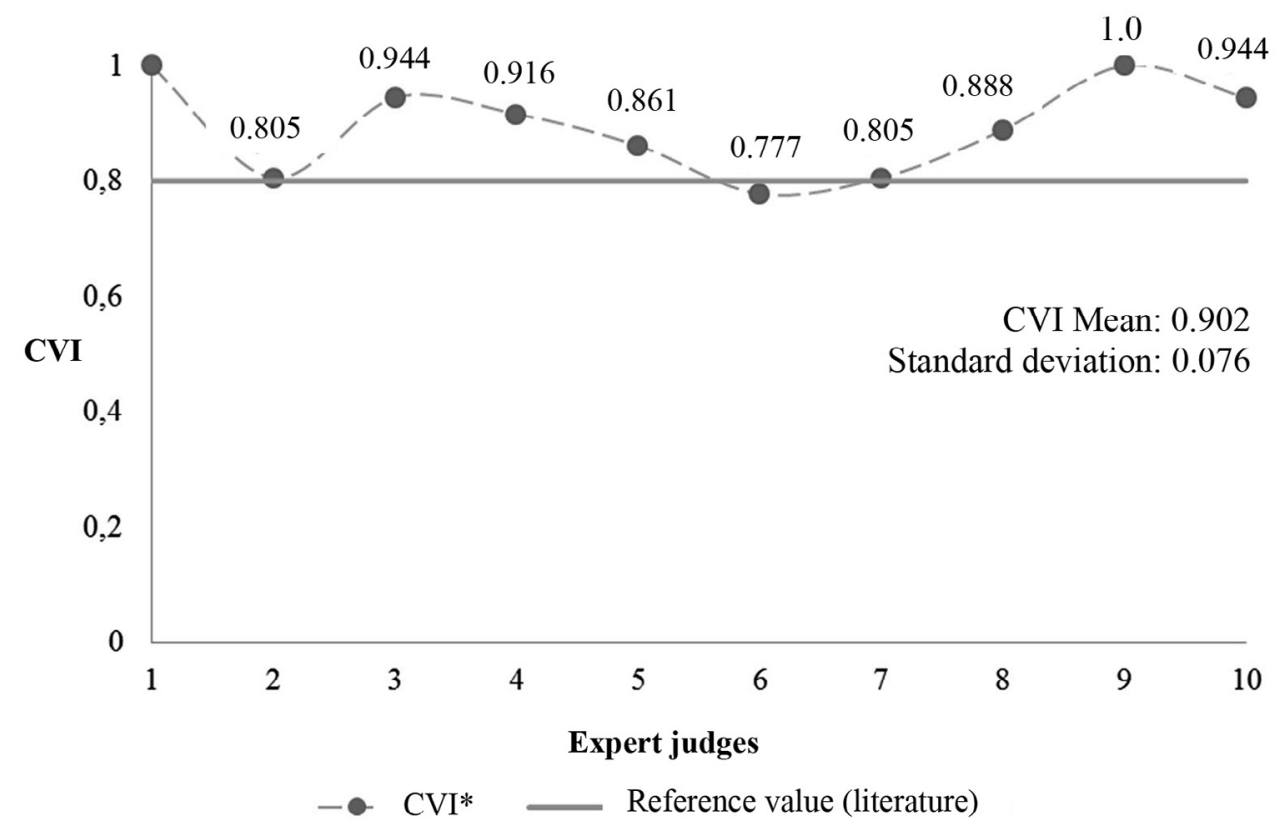

Figure 2 - Content Validation of the instrument to assess the quality of hospital infection control programs, Brazil, $2018(n=10)$ Source: Research data, 2018. 
Table 1 - Presentation of the content validity index of the ten expert judges, Brazil, $2018(n=10)$

\begin{tabular}{|c|c|c|c|}
\hline Participants & $\begin{array}{c}\text { Equivalent or absolutely } \\
\text { equivalent items* }\end{array}$ & Non-equivalent items & $\begin{array}{l}\text { Content Validity Index } \\
\text { (CVI) }\end{array}$ \\
\hline Expert Judge 01 & 36 & 0 & 1.00 \\
\hline Expert Judge 02 & 30 & 6 & 0.833 \\
\hline Expert Judge 03 & 34 & 2 & 0.944 \\
\hline Expert Judge 04 & 34 & 2 & 0.944 \\
\hline Expert Judge 05 & 31 & 5 & 0.861 \\
\hline Expert Judge 06 & 31 & 5 & 0.861 \\
\hline Expert Judge 07 & 29 & 7 & 0.805 \\
\hline Expert Judge 08 & 32 & 4 & 0.888 \\
\hline Expert Judge 09 & 36 & 0 & 1.00 \\
\hline Expert Judge 10 & 34 & 2 & 0.944 \\
\hline Mean & 32 & 3 & 0.908 \\
\hline Standard deviation & 3 & 2.3 & 0.064 \\
\hline
\end{tabular}

Source: Research data, 2018.

* Number of responses for items that received a score of 3 or 4 on the Likert scale.

Table 2 - Evaluation of Cronbach's alpha test for the instrument to assess hospital infection control program*, Brazil, 2018

\begin{tabular}{lcccc} 
Item description & $\begin{array}{c}\text { Scale mean, if item } \\
\text { was excluded }\end{array}$ & $\begin{array}{c}\text { Scale variance, if } \\
\text { item was excluded }\end{array}$ & $\begin{array}{c}\text { Corrected correlation } \\
\text { between item and } \\
\text { total }\end{array}$ & $\begin{array}{c}\text { Alpha, if the item } \\
\text { was excluded }\end{array}$ \\
\hline Question 1 & 23.83 & 24.866 & 0.422 & 0.808 \\
Question 2 & 23.27 & 26.005 & 0.278 & 0.813 \\
Question 3 & 23.25 & 25.762 & 0.398 & 0.810 \\
Question 4 & 23.68 & 24.236 & 0.519 & 0.803 \\
Question 5 & 23.16 & 26.948 & 0.094 & 0.817 \\
Question 6 & 23.51 & 26.181 & 0.129 & 0.820 \\
Question 7 & 23.20 & 26.623 & 0.162 & 0.816 \\
Question 8 & 23.25 & 25.802 & 0.368 & 0.811 \\
Question 9 & 23.22 & 26.633 & 0.132 & 0.817 \\
Question 10 & 23.25 & 26.262 & 0.219 & 0.815 \\
Question 11 & 23.31 & 25.825 & 0.293 & 0.813 \\
Question 12 & 23.29 & 25.677 & 0.354 & 0.811 \\
\hline
\end{tabular}


Table 2 - Cont.

\begin{tabular}{|c|c|c|c|c|}
\hline Item description & $\begin{array}{l}\text { Scale mean, if item } \\
\text { was excluded }\end{array}$ & $\begin{array}{l}\text { Scale variance, if } \\
\text { item was excluded }\end{array}$ & $\begin{array}{l}\text { Corrected correlation } \\
\text { between item and } \\
\text { total }\end{array}$ & $\begin{array}{l}\text { Alpha, if the item } \\
\text { was excluded }\end{array}$ \\
\hline Question 13 & 23.26 & 25.452 & 0.464 & 0.808 \\
\hline Question 14 & 23.89 & 25.635 & 0.276 & 0.813 \\
\hline Question 15 & 23.38 & 24.715 & 0.514 & 0.805 \\
\hline Question 16 & 23.93 & 25.641 & 0.293 & 0.813 \\
\hline Question 17 & 23.25 & 26.067 & 0.281 & 0.813 \\
\hline Question 18 & 23.54 & 24.888 & 0.394 & 0.809 \\
\hline Question 19 & 23.22 & 25.872 & 0.426 & 0.810 \\
\hline Question 20 & 23.56 & 24.903 & 0.385 & 0.809 \\
\hline Question 21 & 23.73 & 24.713 & 0.424 & 0.808 \\
\hline Question 22 & 23.58 & 24.069 & 0.56 & 0.802 \\
\hline Question 23 & 23.47 & 24.375 & 0.528 & 0.803 \\
\hline Question 24 & 23.40 & 24.738 & 0.487 & 0.806 \\
\hline Question 25 & 23.45 & 27.223 & -0.080 & 0.827 \\
\hline Question 26 & 23.43 & 26.194 & 0.141 & 0.819 \\
\hline Question 27 & 23.58 & 25.874 & 0.183 & 0.818 \\
\hline Question 28 & 23.27 & 25.81 & 0.337 & 0.812 \\
\hline Question 29 & 23.62 & 25.494 & 0.257 & 0.815 \\
\hline Question 30 & 23.35 & 24.902 & 0.493 & 0.806 \\
\hline Question 31 & 23.51 & 26.535 & 0.057 & 0.822 \\
\hline Question 32 & 23.62 & 25.529 & 0.250 & 0.815 \\
\hline Question 33 & 23.25 & 26.842 & 0.039 & 0.819 \\
\hline Question 34 & 23.27 & 26.005 & 0.278 & 0.813 \\
\hline Question 35 & 23.58 & 24.069 & 0.560 & 0.802 \\
\hline Question 36 & 23.16 & 26.948 & 0.094 & 0.817 \\
\hline
\end{tabular}

Source: Research data, 2018

*Cronbach's alpha: 0.82; Mean: 24.15; Variance: 24; Standard deviation: 5.2.

The instrument has 36 questions that were stratified into 15 items of structure assessment, 16 related to the process and five directed to the result. After adjustments, the provisional version of the instrument was accomplished, with the scientific and social delivery of the article represented in Chart 1. The items must be accompanied by the options "yes", "partially" and "no", excluding the rule for questions number 21 and 22. 


\section{Structure}

(1) Does your region have a Central Public Health Laboratory (CPHL)?

(2) Does your institution have its own microbiology laboratory or a third party?

(3) Is there basic sanitation in your health service region?

(4) Do you consider that there is adequate ventilation in your institution?

(5) Does your work institution periodically monitor water quality?

(6) Does your work institution periodically monitor air quality?

(7) Does your institution have a HICC and HICS structured in accordance with current legislation?

(8) Does the structure of your institution contribute to hand hygiene effectively?

(9) Are there sinks and/or dispensers for alcohol and/or liquid soap at all service points?

(10) Does your institution have a Health Solid Waste Management Program (HSWMP) described and validated?

(11) Is there an overcrowding of patients in your work institution?

(12) Do you consider that the health professionals that compose the multidisciplinary team are overloaded?

(13) Does your institution have at least 1 (one) meter of bed spacing between patients?

(14) Do you consider that your institution has an adequate structure to serve patients during an epidemic or pandemic?

(15) Does your institution adopt cohort isolation for patients under specific precautions?

\section{Process}

(16) The patient safety protocols are implemented at the institution?

(17) Does HICS know and validate the cleaning and disinfection protocols for surfaces?

(18) Does your institution perform cleaning, preparation, sterilization, disinfection and storage of health products?

(19) Do HICS professionals develop protocols based on scientific evidence?

(20) Do stakeholders (strategic public) participate in the elaboration of HICS protocols and guidelines?

(21) What criterion does HICS adopt for surveillance of HAls?

(22) What surveillance method does HICS adopt?

\begin{tabular}{|c|c|c|}
\hline Yes & Partially & No \\
\hline Yes & Partially & No \\
\hline Yes & Partially & No \\
\hline Yes & Partially & No \\
\hline Yes & Partially & No \\
\hline Yes & Partially & No \\
\hline Yes & Partially & No \\
\hline Yes & Partially & No \\
\hline Yes & Partially & No \\
\hline Yes & Partially & No \\
\hline Yes & Partially & No \\
\hline Yes & Partially & No \\
\hline Yes & Partially & No \\
\hline Yes & Partially & No \\
\hline Yes & Partially & No \\
\hline
\end{tabular}




\section{Structure}

(23) Does your institution monitor the use of antibiotics through an Antimicrobial Use Management Program?

(24) Has your institution implemented protocols on standard, contact, droplet and aerosol precautions?

(25) Does your institution implement the multimodal strategy for improving hand hygiene?

(26) Does your institution have other multimodal strategies related to the prevention and control of HAls?

(27) Do medical professionals actively participate in the training defined by HICS?

(28) Does the nursing team actively participate in the training defined by the HICS?

(29) Does the physiotherapy team actively participate in the training defined by HICS?

(30) Do administrative professionals and the management team receive training from HICS?

(31) Does HICS conduct sectoral audits periodically in the assistance sectors?

\section{Result}

(32) Does the HICS identify outbreaks in a timely manner through infectious indicators and establish control measures?

(33) Are the results of the bundles disclosed to your institution for the prevention and control of HAls?

(34) Does the HICS carry out a survey of the Health Care Related Infection indicators and disclose it widely to the entire institution?

(35) Does the HICS prioritize problems based on the Health Care Related Infection indicators?

(36) Do HICS professionals periodically provide feedback on infectious indicators to the multidisciplinary team?

\begin{tabular}{|c|c|c|}
\hline Yes & Partially & No \\
\hline Yes & Partially & No \\
\hline Yes & Partially & No \\
\hline Yes & Partially & No \\
\hline Yes & Partially & No \\
\hline Yes & Partially & No \\
\hline Yes & Partially & No \\
\hline Yes & Partially & No \\
\hline
\end{tabular}

Chart 1 - Cont.

Source: Research data, 2018

\section{DISCUSSION}

The HICP is established in a diversified way in Brazil and for this reason, creating and validating an assessment instrument is complex. This fact may be related to the requirement to reproduce consistent results in the face of national heterogeneity. In addition, health services have weaknesses in the organizational context that make it difficult to compile data and measure infection control indicators ${ }^{(7-8)}$.
In this study, the questions of the instrument were categorized among the components of structure, process and result. This categorization of items reinforces the importance of professionals to encompass the various actions with a view to the maximum reduction of infectious diseases. The HICP success depends on the institutional policy that should be stimulated as a triad of multidisciplinary interest ${ }^{(15)}$.

When considering the assessment instrument, the conformity calculation directs the numerator to the items served 
and the denominator to the total number of questions in the instrument, multiplied by 100 . The literature does not standardize the minimum percentage for determining the HICP quality status. However, similar research conducted in Brazil found an average compliance of over $80 \%$ for indicators of technical-operational structure and HAls epidemiological surveillance system, this value being indicated as a reference in this study ${ }^{(7)}$.

It is understood that the structure and the process are considered essential elements for the implementation of actions that will impact the assistance results. Research carried out in Germany reinforced the scarcity of studies focused on the two quality components and proposed a national survey to find out the positive and negative aspects of 736 hospitals. The workload and multimodal strategies were highlighted as opportunities for improvement between services ${ }^{(16)}$. It is noteworthy that these two assessment items were also included in the instrument proposed in this research.

In addition, the instrument to assess hospital infection control programs included other items that covered, in some way, the central components proposed by the World Health Organization (WHO) (2). The HICP itself and its guidelines stand out, the permanent education of the multidisciplinary team, the surveillance of HAls, monitoring, audits and feedback of results, as well as hospital occupation, materials and equipment.

Researchers claim that several instruments have been inadequately validated because they do not comply with the fundamentals of reliability, stability, internal consistency and equivalence, which can compromise the quality of the responses in relation to what is proposed to be measured ${ }^{(12,14)}$. The present study sought scientific references to ensure a careful evaluation of the expert judges to guarantee the reliability of the items. The tool construction process involved careful methodological stages to make it appropriate, which represented the advance of current knowledge due to the use of psychometric properties to give theoretical support to the tool to be measured.

To increase the accuracy related to the validation of the measurement properties, ten expert judges were included. The ideal number can vary between five and ten professionals with knowledge ${ }^{(17)}$. Reading stratified by question is indicated, seeking the best agreement among the participants. In this case, the CVI becomes a good strategy for analyzing the proportion of a particular question to validate the instrument as a whole ${ }^{(12,14)}$.

This study presented a CVI mean score above that recommended by the literature. It is indicated that the proportion of expert judges in agreement remains at least 0.80 , and preferably, equal to or greater than $0.90^{(14)}$. Australian researchers corroborate the data and add that the CVI has characteristics that make it suitable for methodological studies. The ease of interpretation and understanding of the data is attributed, in addition to allowing a detailed review excluding or replacing the item ${ }^{(17-18)}$.

Cronbach's alpha test refers to a statistical technique directly linked to reliability in relation to the quality of the instrument. Authors indicate that ideal values should remain between 0.70 and $1.00^{(12,14)}$. Therefore, it is stated that the results of this research were satisfactory (0.82), reinforcing the power of the tool in measuring what is actually proposed.

In addition, the pre-test applied to 98 participants was considered a differential, since 30 to 40 individuals are recommended in this stage ${ }^{(12)}$. It is noteworthy that there are few professionals working at the HICC with specific degrees, influencing adherence in relation to the guidelines aimed at the prevention and control of HAls ${ }^{(19)}$. For this reason, the strength of the instrument validated in this study is associated with the large participation of professionals with experience, qualifications and academic training in the area.

This study represented an advance for teaching and research, since the methodological stages of construction and validation of the instrument followed strictly all scientific recommendations, using consolidated statistical tests to make the tool reliable and adequate. It is believed that the elaboration of this instrument will allow a complete assessment of infection control programs, supporting discussions that can improve the quality of health in relation to the components of structure, process and result.

However, the research had limitations that must be considered. Each question was composed of a detailed explanation of the references used to construct the item, and may not have required a deep knowledge for individual interpretation. In addition, during the data collection period, WHO released a tool called "Infection prevention and control assessment framework at the facility level", with the objective of supporting the implementation of the central components and conducting a self-assessment of health services ${ }^{(20)}$. Even so, the instrument of this study had previously been validated, sent to the participants and answered by the majority, which made us choose to keep it. It was found that the questions elaborated by the authors, included the content of the WHO.

\section{CONCLUSION}

The study achieved the objective that was proposed, building and validating the instrument in relation to the components of structure, process and result. The tool has become a good option for infection controllers, reinforcing a multifaceted assessment for quality assurance in the area. The psychometric properties have proven to be reliable and can be used efficiently to assess hospital infection control programs at the national level. This study may stimulate 
the continuous improvement of infection control services to verify quality items that will assist effective planning to achieve consistent results.

\section{REFERENCES}

1. Salmanov A, Vozianov S, Kryzhevsky V, Litus O, Drozdova A, Vlasenko I. Prevalence of healthcare-associated infections and antimicrobial resistance in acute care hospitals in Kyiv, Ukraine. J Hosp Infect. 2019;102(4):431-37. doi: https://doi.org/10.1016/j.jhin.2019.03.008

2. Storr J, Twyman A, Zingg W, Damani N, Kilpatrick C, Reilly J et al. Core components for effective infection prevention and control programmes: new WHO evidence-based recommendations. Antimicrob Resist Infect Control. 2017;6:6. doi: https://doi.org/10.1186/s13756-016-0149-9

3. Ministério da Saúde (BR). Portaria n. 2.616, de 12 de maio de 1998. Dispõe sobre diretrizes e normas para a prevenção e o controle das infecções hospitalares. Brasília; 1998 [cited 2020 Apr 10]. Available from: http://bvsms.saude.gov.br/ bvs/saudelegis/gm/1998/prt2616_12_05_1998.html

4. Gilmartin HM, Sousa KH. Testing the Quality Health Outcomes Model Applied to Infection Prevention in Hospitals. Qual Manag Health Care. 2016;25(3):149-61. doi: https://doi.org/10.1097/QMH.0000000000000102

5. Gardner G, Gardner A, O'Connell J. Using the Donabedian framework to examine the quality and safety of nursing service innovation. J Clin Nurs. 2014;23(12):145-55. doi: https://doi.org/10.1097/10.1111/jocn.12146

6. Días C, Lerena RG, Peralta N, Tiseira P. Autoevaluación de programas de prevención y control de infecciones associadas al cuidado de la salud. Rev Argent Salud Pública. 2018 [cited 2020 Apr 10];9(37):43-6. Available from: http://sgc. anlis.gob.ar/bitstream/123456789/613/1/RevArgSP2018v9n37a07.pdf

7. Giroti ALB, Ferreira AM, Rigotti MA, Sousa AFL, Frota OP, Andrade D. Hospital infection control programs: assessment of process and structure indicators. Rev Esc Enferm USP. 2018;52:e03364. doi: https://doi.org/10.1590/ s1980-220x2017039903364

8. Padoveze MC, Fortaleza CM, Kiffer C, Barth AL, Carneiro IC, Giamberardino HI et al. Structure for prevention of health care-associated infections in Brazilian hospitals: a countrywide study. Am J Infect Control. 2016;44(1):74-9. doi: https://doi.org/10.1016/j.ajic.2015.08.004

9. Menegueti MG, Canini SRMS, Bellissimo-Rodrigues F, Laus AM. Avaliação dos programas de controle de infecção hospitalar em serviços de saúde. Rev Latino-Am Enfermagem. 2015;23(1):98-105. doi: https://doi. org/10.1590/0104-1169.0113.2530

\section{- Corresponding author:}

André Luiz Silva Alvim

Email: andrealvim1@hotmail.com
10. Alves DCI, Lacerda RA. Evaluation of Programs of Infection Control related to Healthcare Assistance in Hospitals. Rev Esc Enferm USP. 2015;49(spe):65-73. doi: https://doi.org/10.1590/S0080-623420150000700010

11. Silva CPR, Lacerda RA. Validação de proposta de avaliação de programas de controle de infecção hospitalar. Rev Saúde Pública. 2011;45(1):121-8. doi: https://doi.org/10.1590/S0034-89102010005000052

12. Coluci MZO, Alexandre NMC, Milani D. Construção de instrumentos de medida na área da saúde. Ciênc Saúde Coletiva. 2015;20(3):925-36. doi: https://doi. org/10.1590/1413-81232015203.04332013

13. Pereira RDM, Alvim NAT. Delphi technique in dialogue with nurses on acupuncture as a proposed nursing intervention. Esc Anna Nery. 2015 [cited 2020 Apr 15];19(1):174-80. Available from: https://www.scielo.br/pdf/ean/ v19n1/en_1414-8145-ean-19-01-0174.pdf

14. Souza AC, Alexandre NMC, Guirardello EB. Psychometric properties in instruments evaluation of reliability and validity. Epidemiol Serv Saúde. 2017;26(3):649-59. doi: https://doi.org/10.5123/s1679-49742017000300022

15. Rabaan AA, Alhani HM, Bazzi AM, Al-Ahmed SH. Questionnaire-based analysis of infection prevention and control in healthcare facilities in Saudi Arabia in regards to Middle East Respiratory Syndrome. J Infect Public Health. 2017;10(5):548-63. doi: https://doi.org/10.1016/j.jiph.2016.11.008

16. Aghdassi SJS, Hansen S, Bischoff P, Behnke M, Gastmeier P. A national survey on the implementation of key infection prevention and control structures in German hospitals: results from 736 hospitals conducting the WHO Infection Prevention and Control Assessment (IPCAF). Antimicrob Resist Infect Control. 2019;8(73):1-8. doi: https://doi.org/10.1186/s13756-019-0532-4

17. Almanasreh E, Moles R, Chen TF. Evaluation of methods used for estimating content validity. Res Social Adm Pharm. 2019;15(2):214-21. doi: https://doi. org/10.1016/j.sapharm.2018.03.066

18. Lassetter JH, Macintosh Cl, Williams M, Driessnack M, Ray G, Wisco JJ. Psychometric testing of the healthy eating and physical activity self-efficacy questionnaire and the healthy eating and physical activity behavior recall questionnaire for children. J Spec Pediatr Nurs. 2018;23(2):e12207. doi: https:// doi.org/10.1111/jspn. 12207

19. Stone PW, Pogorzelska-Maziarz M, Herzig CT, Weiner LM, Furuya EY, Dick A et al. State of infection prevention in US hospitals enrolled in the National Health and Safety Network. Am J Infect Control. 2014;42(2):94-9. doi: https://doi. org/10.1016/j.ajic.2013.10.003

20. World Health Organization (CH). Infection Prevention and Control Assessment Framework at the facility level. Geneva: WH0; 2018 [cited 2020 Apr 18]. Available from: https://www.who.int/infection-prevention/tools/corecomponents/IPCAF-facility.PDF?ua=1

\section{Associate editor: \\ Cecília Helena Glanzner}

Received: 06.03.2020

Approved: 08.04.2020

\section{Editor-in-chief:}

Maria da Graça Oliveira Crossetti 